\title{
Genetic Variants of Haemophilia B Detected by Immunoradiometric Assay: Implications for Prenatal Diagnosis
}

\author{
ROLF LJUNG ${ }^{(23)}$ AND LARS HOLMBERG \\ Department of Paediatrics and Coagulation Laboratory, University of Lund, Malmö General Hospital, Malmö,
} Sweden

\section{Summary}

Fifty patients with haemophilia B, belonging to 29 kindreds, were investigated with a highly sensitive immunoradiometric assay based on a homologous antibody to factor IX. The assay measures factor IX antigen (f.IX:Ag) in plasma down to $0.025 \mathrm{U} / \mathrm{dl}$. Seventeen of 18 investigated patients with severe haemophilia $B$ had very little or no f.IX:Ag. Also four of nine patients with moderately severe disease had very low antigen levels, approximately equal to their factor IX clotting activity (f.IX:C), whereas the other 5 had antigen in excess of activity.

Of the 23 investigated patients with mild haemophilia $B, 20$ had f.IX:Ag approximately equal to f.IX:C, whereas 3 had normal amounts of antigen. One family with mild disease was found to have a possible variant of haemophilia B Leyden, earlier described in a few families with moderately severe disease. No haemophilia $B_{M}$ variants, chararcterized by prolonged prothrombin time with bovine brain thromboplastin, were found. We have shown earlier that the immunoradiometric assay of f.IX was useful in the prenatal evaluation of one fetus at risk for haemophilia $B$. The present study shows that the assay can be applied for prenatal diagnostic purposes in the vast majority of carriers of severe haemophilia $B$ and in about half of the carriers of moderately severe disease.

\section{Speculation}

Further knowledge of the genetic variation of haemophilia $B$ might be acquired if plasmas from the patients were tested with different, homologous as well as heterologous antisera. Such studies would perhaps not only reveal an even greater genetic complexity but make it possible to use immunoradiometric assays in all instances where prenatal evaluation is indicated of a fetus at risk for haemophilia $B$.

Haemophilia B is usually classified as severe, moderate or mild, according to the level of factor IX clotting activity (f.IX:C). The existence of molecular variants of haemophilia B was detected after it had become possible to determine factor IX antigen (f.IX: Ag) using different assays $(1,7,9,11,14,15,16,17,19,20,21$, 22). Cross reacting material negative $\left(\mathrm{CRM}^{-}\right)$variants have no demonstrable f.IX:Ag; $\mathrm{CRM}^{+}$variants have normal amounts, and $\mathrm{CRM}_{\mathrm{R}}$ designates variants that have amounts reduced more or less proportionally to f.IX:C. $B_{M}$ variants are characterized by prolonged prothrombin time with bovine brain thromboplastin $(6,8)$. Most of the immunologic f.IX methods described are not very sensitive and they all depend upon the specificity of the antibody used. Only one method seems to have been capable of detecting f.IX:Ag levels below $2 \%$ of normal (20). Detailed reports of cases with antigen content below $10 \%$ of normal are still scanty.

A very sensitive immunoradiometric assay using a homologous antibody has recently been described and used in the prenatal diagnosis of one case of haemophilia B (4). In the present study 50 haemophilia B patients were investigated with this immuno- radiometric assay in order to characterize genetic variants including those with very low levels of f.IX:Ag. The practical purpose of the study was to ascertain to what extent immunologic methods are applicable in prenatal diagnosis of haemophilia $\mathbf{B}$.

\section{MATERIALS AND METHODS}

Patients. The study group consisted of 50 patients with haemophilia B belong to 29 kindreds. All the patients were informed about the purpose of the investigation and gave their consent. The disease was severe in 18 of the patients (f.IX:C $<1 \mathrm{U} / \mathrm{dl}$ ), moderately severe in 9 , (f.IX:C $=1-4 \mathrm{U} / \mathrm{dl}$ ) and mild (f.IX:C=5$25 \mathrm{U} / \mathrm{dl}$ ) in 23. ( $1 \mathrm{U}=$ the factor IX activity, f.IX:C, in $1 \mathrm{ml}$ of pooled normal human plasma).

Collection of blood. Citrated plasma, obtained and prepared as described elsewhere (12), was frozen immediately and stored at $-60^{\circ} \mathrm{C}$ until examined.

Factor IX clotting activity (f.IX:C) was determined in a onestage recalcification system with plasma from a patient with severe haemophilia B as test base (13). Normal range is 60-140\%.

Factor IX clotting antigen (f.IX:Ag) was determined with an immunoradiometric assay (4). Serum from a patient with haemophilia B, who had developed an inhibitor to f.IX, was used as source of antibody. The titre against f.IX was $5000 \mathrm{U} / \mathrm{dl}$ (one unit is defined as the amount that neutralizes $1 \mathrm{U}$ of f.IX during incubation for $2 \mathrm{~h}$ at $37^{\circ} \mathrm{C}$. One $\mathrm{U} / \mathrm{dl}$ is approximately equal to 2 Bethesda $\mathrm{U} / \mathrm{dl}$ ). The method is described in detail elsewhere (4).

When normal plasma was tested, a linear dose response curve was obtained for dilutions $1 / 128-1 / 2048$. The mean and standard deviation in 24 normals were $108 \pm 27 \mathrm{U} / \mathrm{dl}$. f.IX:C in the same samples was $95 \pm 24 \mathrm{U} / \mathrm{dl}$. The coefficient of correlation between antigen and activity was $0.74(P<0.001)$. The lowest concentration of f.IX:Ag that can be measured is $0.025 \mathrm{U} / \mathrm{dl}$, i.e., $0.025 \%$. No detectable f.IX:Ag is here expressed as $<0.1 \mathrm{U} / \mathrm{dl}$. At low levels $(1: 100,1: 1000,1: 2000)$ of normal pooled plasma, the interand intra-assay coefficients of variation are always less than $10 \%$.

Prothrombin and Proconvertin was measured according to the method of Owren (15), which measures the sum of the vitamin Kdependent coagulation factors, i.e., prothrombin, factor VII and factor X. Normal range is $80-120 \%$.

Thrombotest, which is a variant of the prothrombin and proconvertin method, using ox brain thromboplastin, was performed by thrombotest reagent from Nyegaard, Oslo, Norway. Normal range is $80-120 \%$.

One-stage prothrombin time was determined by the method of Owren using thromboplastin prepared from human and bovine brains (14).

\section{RESULTS}

Table 1 gives the families with severe haemophilia B. Thirteen of the patients had no demonstrable antigen and four had a very small amount (below $1 \mathrm{U} / \mathrm{dl}$ ). Patients $3: 1$ and 4:1 had had an 
Table 1. F.IX:C and F.IX:Ag in 18 patients with severe haemophilia $B$

\begin{tabular}{|c|c|c|}
\hline $\begin{array}{l}\text { Family: } \\
\text { Patient no. }\end{array}$ & $\begin{array}{c}\text { F.IX:C }(\mathrm{U} / \mathrm{dl}) \\
\text { normal range } \\
60-140 \%\end{array}$ & $\begin{array}{c}\text { F.IX:Ag }(\mathrm{U} / \mathrm{dl}) \\
\text { normal range } \\
54-162 \%\end{array}$ \\
\hline $1: 1$ & $<1$ & $<0.1$ \\
\hline $1: 2$ & $<1$ & $<0.1$ \\
\hline $2: 1$ & $<1$ & $<0.1$ \\
\hline $2: 2$ & $<1$ & $<0.1$ \\
\hline $2: 3$ & 3 & $0.9^{\prime}$ \\
\hline $3: 1$ & $<1$ & $<0.1^{2}$ \\
\hline $4: 1$ & $<1$ & $<0.1^{2}$ \\
\hline $5: 1$ & $<1$ & $<0.1$ \\
\hline $6: 1$ & $<1$ & $<0.1$ \\
\hline $7: 1$ & $<1$ & $<0.1$ \\
\hline $8: 1$ & $<1$ & $<0.1$ \\
\hline $9: 1$ & $<1$ & $<0.1$ \\
\hline $10: 1$ & $<1$ & $<0.1$ \\
\hline $11: 1$ & $<1$ & 0.2 \\
\hline $12: 1$ & $<1$ & 0.5 \\
\hline $13: 1$ & $<1$ & 0.5 \\
\hline $14: 1$ & $<1$ & 0.6 \\
\hline $15: 1$ & $<1$ & 26.0 \\
\hline
\end{tabular}

' 2:3 had received F.IX concentrate 5 days prior to examination.

$23: 1$ and 4:1 had developed an anticoagulant against factor IX.

Table 2. F.IX:C and F.IX:Ag in 9 patients with moderate haemophilia $B$

\begin{tabular}{ccc}
\hline $\begin{array}{c}\text { Family: } \\
\text { patient no. }\end{array}$ & $\begin{array}{c}\text { F.IX:C }(\mathrm{U} / \mathrm{dl}) \\
\text { normal range } \\
60-140 \%\end{array}$ & $\begin{array}{c}\text { F.IX:Ag }(\mathrm{U} / \mathrm{dl}) \\
\text { normal range } \\
54-162 \%\end{array}$ \\
\hline $16: 1$ & 1 & 1.5 \\
$16: 2$ & 3 & 4.0 \\
$17: 1$ & 4 & $1.7^{1}$ \\
$18: 1$ & 3 & 2.0 \\
$19: 1$ & 1 & 26.0 \\
$19: 2$ & 1 & 30.0 \\
$20: 1$ & 2 & 35.0 \\
$20: 2$ & 2 & 36.0 \\
$21: 1$ & 3 & 44.0 \\
\hline
\end{tabular}

$17: 1$ is a heterozygous woman with an unusually low level of F.IX:C.

anticoagulant against f.IX for many years. Of the 18 patients with the severe type of the disease, only one had antigen in excess of activity, but still in the subnormal range $(26 \mathrm{U} / \mathrm{dl})$.

Table 2 shows the families with moderate haemophilia B. Two groups could be distinguished. In the first, f.IX:Ag was approximately equal to f.IX:C (4 patients from 3 kindreds). In the second, antigen was much higher than activity, but still in the subnormal range ( 5 patients from 3 kindreds). Members of the same family always had the same pattern and there was no difference in clinical severity between the two groups. One patient, 17:1, was a heterozygous woman with an unusually low level of f.IX (2).

Table 3 shows the families with mild haemophilia B. Two groups could be distinguished. In the first, f.IX:Ag was approximately equal to f.IX:C ( 18 patients from 5 kindreds) and in the second, f.IX:A exceeded the activity and was in the normal range ( 3 patients from 3 kindreds). Members of the same family always had the same pattern except in family 27 . Figure 1 shows the largest family with 8 affected members, all of whom had subnormal and very similar f.IX:Ag levels.

In family 27 , two twin brothers, born in 1953 , were found to have mild haemophilia $B$ in 1960 . Their $f . I X: C$ values at that time were $18 \mathrm{U} / \mathrm{dl}$ and $25 \mathrm{U} / \mathrm{dl}$, respectively. Mild haemophilia B was diagnosed in their brother, two years older, 27:1 in 1956. His f.IX: $\mathrm{C}$ at that time was $12 \mathrm{U} / \mathrm{dl}$. When the family was reexamined in the present investigation we found repeatedly normal values in $27: 2$ and $27: 3$ and $4 \mathrm{U} / \mathrm{dl}$ in $27: 1$.
All investigated patients had normal prothrombin and proconvertin and one-stage prothrombin time, tested with human brain thromboplastin.

Thrombotest and one-stage prothrombin time with bovine brain thromboplastin were performed in all the patients in order to find out whether any had the $B_{M}$ variant. The values for both thrombotest and prothrombin time proved normal in all the patients.

\section{DISCUSSION}

We investigated 50 patients with haemophilia $B$ by a new immunoradiometric assay based on a human antibody. Our assay can detect f.IX:Ag down to a concentration of at least $0.025 \%$ of that in normal plasma and has a high degree of accuracy and reproducibility also at very low levels. It is therefore suitable also for examining patients with low levels of f.IX:Ag and capable of revealing a possible heterogeneity in this group.

Of the 18 patients examined with severe haemophilia B, 13 had no detectable f.IX:Ag, 4 had tiny amounts (below $1 \mathrm{U} / \mathrm{dl}$ ) and one a substantial amount $(26 \mathrm{U} / \mathrm{dl})$. Thus a fairly uniform pattern was found in severe haemophilia $B$. The results obtained with our

Table 3. F.IX:C and F.IX:Ag in 23 patients with mild haemophilia $B$

\begin{tabular}{|c|c|c|}
\hline $\begin{array}{c}\text { Family: } \\
\text { patient no. }\end{array}$ & $\begin{array}{c}\text { F.IX:C }(\mathrm{U} / \mathrm{dl}) \\
\text { normal range } \\
60-140 \%\end{array}$ & $\begin{array}{c}\text { F.IX:Ag }(\mathrm{U} / \mathrm{dl}) \\
\text { normal range } \\
54-162 \%\end{array}$ \\
\hline $22: 1$ & 10 & 9 \\
\hline $22: 2$ & 16 & 10 \\
\hline $22: 3$ & 15 & 12 \\
\hline $22: 4$ & 15 & 12 \\
\hline $22: 5$ & 28 & 13 \\
\hline $22: 6$ & 36 & 14 \\
\hline $22: 7$ & 12 & 16 \\
\hline $22: 8$ & 39 & 16 \\
\hline $23: 1$ & 16 & 9 \\
\hline $23: 2$ & 28 & 13 \\
\hline $23: 3$ & 26 & 18 \\
\hline $24: 1$ & 22 & 12 \\
\hline $25: 1$ & 15 & 13 \\
\hline $25: 2$ & 21 & 14 \\
\hline $25: 3$ & 21 & 14 \\
\hline $25: 4$ & 18 & 18 \\
\hline $25: 5$ & 27 & 18 \\
\hline $26: 1$ & 37 & 41 \\
\hline $27: 1$ & 4 & 79 \\
\hline $27: 2$ & 89 & $96^{\prime}$ \\
\hline $27: 3$ & 96 & $100^{\prime}$ \\
\hline $28: 1$ & 7 & 110 \\
\hline $29: 1$ & 6 & 115 \\
\hline
\end{tabular}

' 27:2 and 27:3 have been diagnosed as mild haemophiliacs in earlier investigations.

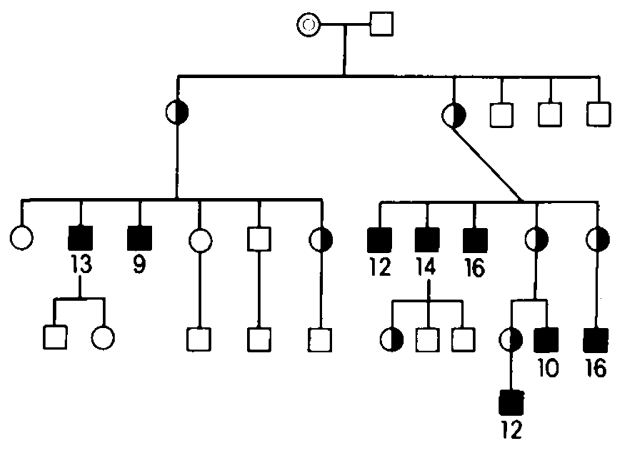

Fig. 1. Pedigree of family 22 with mild haemophilia B. The 8 affected members had very similar f.IX:Ag levels. The carriers status was confirmed by low f.IX:C levels. $O$ indicates a probable carrier. 
immunologic method and with the activity assay (sensitivity limit $1 \mathrm{U} / \mathrm{dl}$ ) were concordant in all cases but one.

Our results differ somewhat from those reported by other workers. Among 10 severe haemophiliacs investigated by Thompson (19), only 2 had f.IX:Ag below $2 \mathrm{U} / \mathrm{dl}$. All the 9 severe haemophiliacs investigated by Yang (22) had low, but still detectable f.IX:Ag (1.1-5.5 U/dl). Only 9 of 35 patients with severe and moderate haemophilia B investigated by Örstavik (14) had f.IX: $\mathrm{Ag}$ below the concentration demonstrable by the method ( $2 \mathrm{U} /$ dl). In the other studies on record $(1,7,9,16,21)$ it was not possible to detect f.IX:Ag levels below 7-10 U/dI).

The difference between our results and those of Thompson, Örstavik and Yang might be explained by differences in specificity of the antiserum used. We use a homologous antibody that can be expected to have a narrow specificity. Heterologous antibodies used by most other workers probably have a broader specificity and thus a higher capacity to detect abnormal molecular variants because they may be directed against a greater number of immuno-reactive sites on the factor IX molecule than homologous antibodies.

About half of the patients with moderate haemophilia B had a very low level of f.IX:Ag i.e., largely equal to their f.IX:C. When severe and moderate haemophilia B were taken together, 21 patients from 17 kindreds had, at most, minute amounts of f.IX: $\mathrm{Ag}$ and could be regarded as $\mathrm{CRM}^{-}$for practical purposes. In contrast, 6 patients from 4 kindreds had substantial amounts and could be classified as $\mathrm{CRM}_{\mathrm{R}}$.

Twenty-three patients with mild haemophilia $B$ were investigated. Twenty of them were $\mathrm{CRM}_{R}$ variants, mostly with f.IX:Ag just as low or even lower than f.IX:C. The remaining three were $\mathrm{CRM}^{+}$variants. These three presumably have a f.IX molecule that is structurally altered so that its antigenic properties are better preserved but its biological activity is not higher than in other patients with mild haemophilia $B$.

In families 22 and 25 , several members were investigated. The range of variation of f.IX:Ag values was narrower than that of f.IX:C values (F-test: variance ratio $19.9, P<0.001$ ). This was certainly because the antigen can be measured with greater accuracy.

In family 27 , the three members were of approximately the same age. Mild haemophilia $B$ had been diagnosed 20 years ago from their f.IX:C values $(12,18$ and $25 \mathrm{U} / \mathrm{dl})$ measured with the same method as today. In the present study, they were investigated several times and we always found normal f.IX:C and f.IX:Ag values in 27:2 and 27:3, but a low f.IX: $C$ value in spite of a normal f.IX:Ag in 27:1. This family might have a haemophilia B Leyden variant, which has been described in a few families with moderate haemophilia $B$ and is characterized by a diminishing bleeding tendency and increasing f.IX:C with increasing age (18). If so, it would mean that a molecular defect had disappeared with time in 2 of the patients.

Haemophilia $B_{M}$ is characterized by a prolonged prothrombin time with bovine thromboplastin $(6,8)$. $B_{M}$ variants were not detected in either the present study or in some earlier studies (17). This is probably because the mutant gene responsible for the $B_{M}$ variant is not widely spread in the world.

Genetic counselling of pregnant carriers of haemophilia, now includes not only a recommendation of fetal sex determination. If the fetus is a male, the woman is offered further prenatal evaluation. Prenatal diagnosis of haemophilia cannot, in our hands, be based upon a clotting assay of fetal blood samples obtained at fetoscopy (10) because such samples are often mixed with amniotic fluid, which disturbs clotting analysis. We have therefore resorted to immunologic methods when examining for haemophilia $B$, as well as haemophilia A, before birth $(3,5)$. Our immunoradiometric method for f.IX:Ag based upon a human antibody has proved useful for that purpose because it is sensitive enough to detect the low levels of the f.IX:Ag present in normal 16-20 wk fetuses (4). Prenatal evaluation of a fetus can only be offered carriers in families with $\mathrm{CRM}^{-}$variants of the disease and should not be attempted in an individual case before the genetic variant in the family has been determined by examination of an affected member. In conclusion, it should be possible to use the immunoradiometric assay for prenatal diagnostic purposes in $80 \%$ of families with severe and moderate haemophilia $B$. In mild haemophilia B, prenatal evaluation of the fetus is not indicated.

\section{REFERENCES AND NOTES}

1. Elödi. S., and Puskas, E.: Variants of haemophilia B. Thromb. Diath. Haemorrh.. 28: 489 ( 1972).

2. Holmberg. L.. Nilsson, I. M., Henriksson. P., and Örstavik, K. H.: Homozygous expression of haemophilia B in a heterozygote. Acta Med. Scand., 204: 231 (1978).

3. Holmberg, L., Borge, L., Ljung. R., and Nilsson. I. M.: Measurement of antihaemophilic factor $\mathrm{A}$ antigen (VIII:CAg) with a solid phase immunoradiometric method based on homologous non-haemophilic antibodies. Scand. J. Haematol., 23: 17 (1979).

4. Holmberg, L.. Gustavii, B., Cordesius, E., Kristoffersson, A. C., Ljung. R. Löberg, L., Strömberg, P., and Nilsson, I. M.: Prenatal diagnosis of haemophilia B by an immunoradiometric assay of f.IX. Blood, 56: 397 (1980).

5. Holmberg, L.: Prenatal diagnosis of congenital bleeding disorders. Acta Paediatr. Scand., 69: 809 (1980).

6. Hougie. C., and Twomey, J. J.: Haemophilia $B_{M}$ : a new type of factor IX deficiency. Lancet, I: 698 (1967).

7. Kasper, C. K., Österud, B., Minami, J. Y., Shonick, W., and Rapaport, S. I.: Hemophilia B: Characterization of genetic variants and detection of carriers. Blood, 50: 351 (1977).

8. Kidd, P.. Denson, K. W. E., and Biggs, R.: The thrombotest reagent and Christmas disease. Lancet, IJ: 522 (1963).

9. Meyer, D., Bidwell, E., and Larrieu, M. J.: Cross-reacting material in genetic variants of haemophilia B. J. Clin. Pathol. 25: 433 (1972).

10. Mibashan, R. S., Rodeck, C. H.. Thumston, J. K., Edwards, R. J., Singer, J. D. and White. J. M.: Plasma assay of fetal factors VIIIC and IX for prenatal diagnosis of haemophilia. Lancet, I: 1309 (1979).

11. Neal, W. R., Tayloe, D. T., Cederbaum, A. I., and Roberts, H. R.: Detection of genetic variants of haemophilia $\mathrm{B}$ with an immunosorbent technique. $\mathrm{Br}$. J. Haematol. 25: 63 (1973).

12. Nilsson. I. M., Blombäck, M., and von Francken, 1.: On an inherited autosoma! hemorrhagic diathesis with antihemophilic globulin (AHF) deficiency and prolonged bleeding time. Acta Med. Scand., 35: 159 (1957).

13. Nilsson. I. M.: Hemorrhagic and thrombotic diseases. pp. 220-223 (John Wiley and Sons. London, 1974).

14. Örstavik, K. H.: Electroimmunoassay of factor IX antigen; Increased sensitivity by enzyme amplification of immunoprecipitates. Thromb. Res., 15:721 (1979).

15. Örstavik, K. H., Österud, B., Prydz, H., and Berg. K.: Electroimmunoassay of factor IX in hemophilia B. Thromb. Res., 7: 373 (1975).

16. Owren. O. A.: A quantitative one-stage method for the assay of prothrombin. Scand. J. Clin. Lab. Invest., I: 81 (1949).

17. Owren, O. A., and Aas. K.: The control of dicumarol therapy and the quantitative determination of prothrombin and proconvertin. Scand. J. Clin. Lab. Invest. 3: 201 (1951).

18. Roberts, H. R., Grizzle. J. E., McLester, W. D., and Penick. (j. D.: Genetic variants of haemophilia B: Detection by means of a specific PTC inhibitor. J Clin. Invest., 47: 360 (1968).

19. Thompson, A. R.: Factor IX antigen by radioimmunoassay. J. ('lin. Invest.. 59. 900 (1977).

20. Veltkamp, J. J., Meilof, J., Remmelts, H. G., van der Vlerk, D., and Loeliger, E. A.: Another genetic variant of haemophilia B: Haemophilia B Leyden. Scand. J. Haemat., 7: 82 (1970).

21. Yang. H. C.: Immunologic studies of factor IX (Christmas factor). I. Counterimmunoelectrophoresis method for factor IX antigen. Thromb. Res.. 13: 97 (1978).

22. Yang, H. C.: Immunologic studies of factor IX (Christmas factor). II. Immunoradiometric assay of factor IX antigen. Br. Haematol., 39: 215 (1978).

23. Requests for reprints should be addressed to: Dr. Rolf Ljung. Department of Paediatrics. Malmö General Hospital, S-214 0I Malmö. Sweden.

24. This research was supported by grants from the Swedish Medical Research Council (B81-19X-()4997-05B), the Medical Research Council of the Swedish Life Insurance Companies, the "Expressen" Prenatal Research Foundation and the Faculty of Medicine of the University of Lund, Sweden.

25. Received for publication April 10, 1981.

26. Accepted for publication July 8,1981 . 